\section{Endoscopic management of gastric wall bleeding and stent blood clot occlusion after endoscopic ultrasound-guided hepaticogastrostomy}
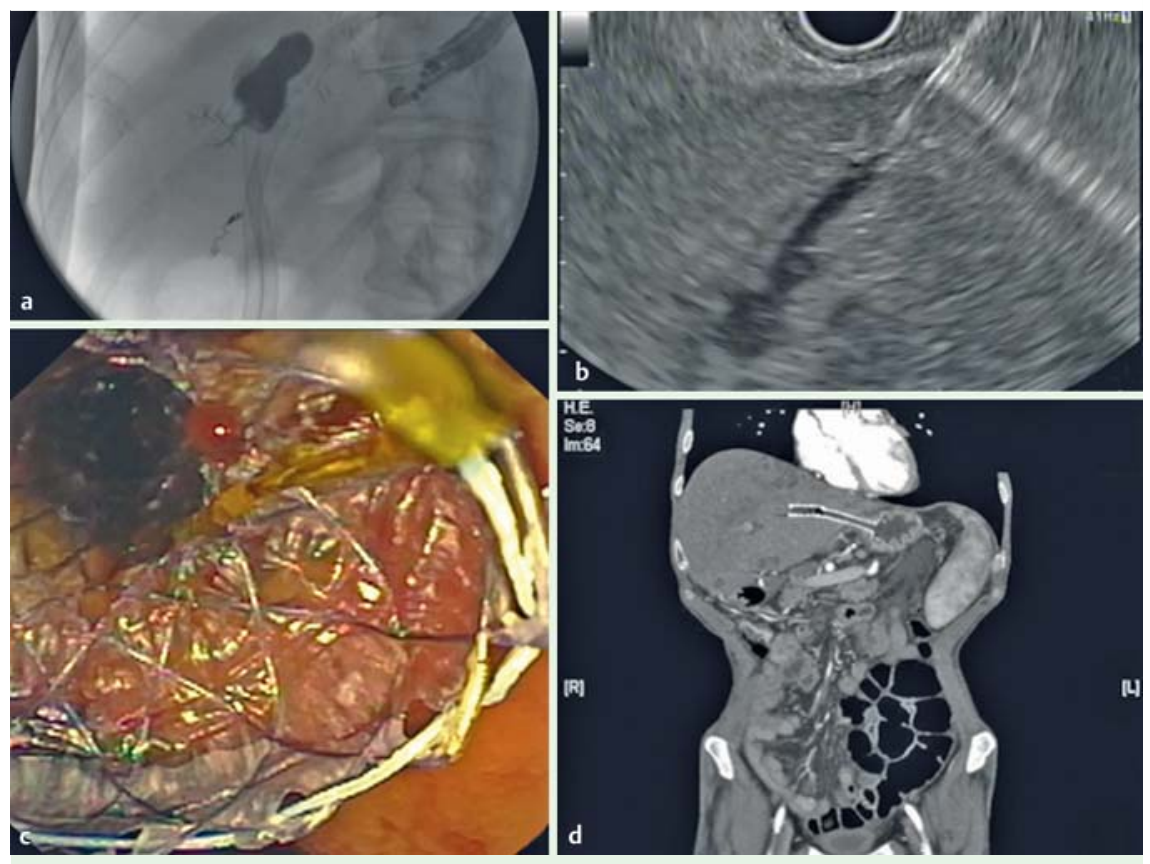

Fig. 1 Hepaticogastrostomy using a partially covered metallic stent after endoscopic retrograde cholangiopancreatography failure in a 58 -year-old man with colon cancer liver metastasis. a Fluoroscopic image after hilum opacification. b Endoscopic ultrasound-guided puncture of the biliary dilatation. c Stent deployment. $\mathbf{d}$ Computed tomography (CT) appearance of the stent after the first hepaticogastrostomy procedure.

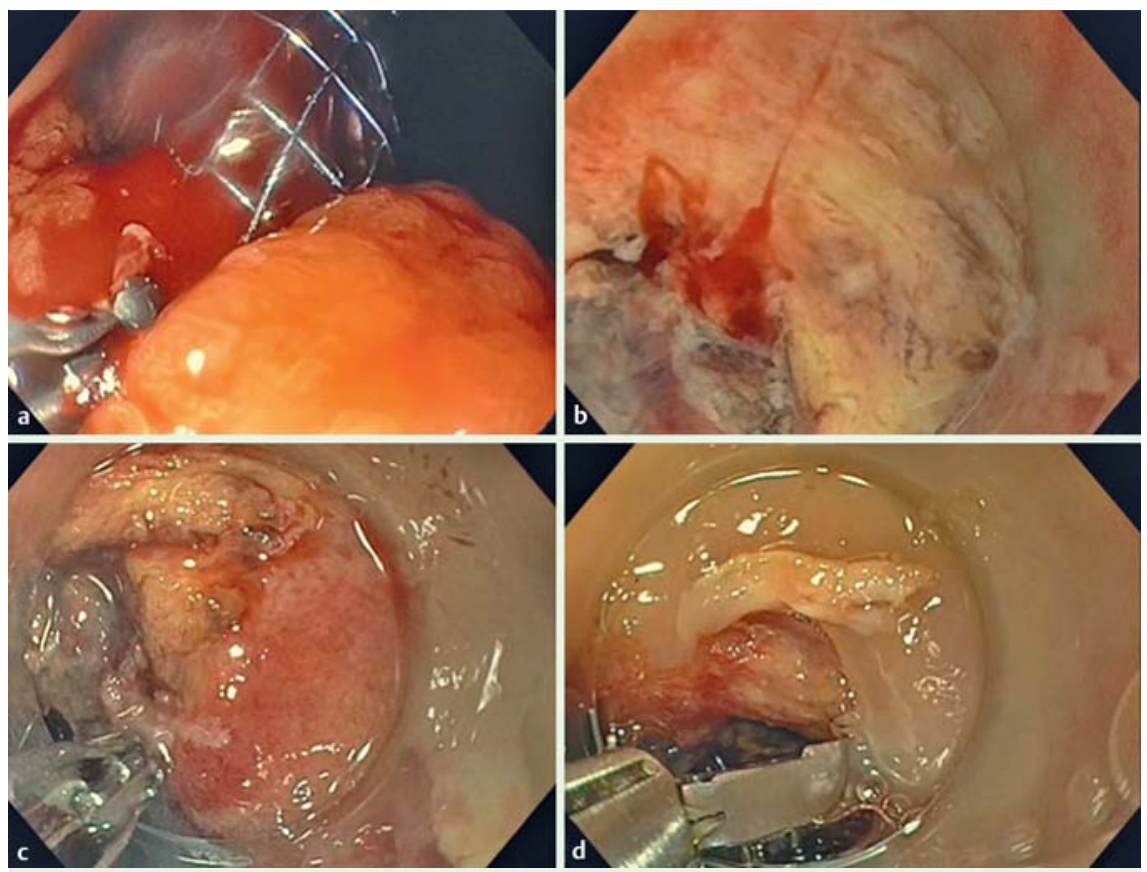

Fig. 2 Management of bleeding. a Active venous bleeding at the upper edge of the stent. $\mathbf{b}$ View under water of the bleeding point. $\mathbf{c}$ Hemostasis using hot biopsy forceps. $\mathbf{d}$ Clipping at the upper edge of the stent.
Hepaticogastrostomy is an alternative to biliary drainage after endoscopic retrograde cholangiopancreatography (ERCP) failure $[1,2]$. However, this technique is associated with higher morbidity, including stent migration [3] and bleeding [4]. Bleeds are mostly due to pseudoaneurysm of the hepatic arteries [5].

We report the case of a 58-year-old man with colon cancer liver metastasis that was compressing the hepatic hilum. Endoscopic ultrasound (EUS)-guided hepaticogastrostomy had been performed after three ERCP failures. After puncture and guidewire placement, a 7.5-Fr cystotome had been used before delivery of a dedicated partially covered metallic stent (Hanarostent; Life Partners Europe, Paris, France). At the end of the procedure good biliary drainage had been obtained without any bleeding ( $\bullet$ Fig. 1, $\bullet$ Video 1 ).

Unfortunately, 7 days later the patient experienced melena and jaundice, and adherent clots were seen in the stent at gastroscopy. We diagnosed active venous bleeding from the gastric wall at the upper edge of the stent ( $\nabla$ Fig. 2). First, we injected $4 \mathrm{~mL}$ of diluted epinephrine and achieved hemostasis using hot biopsy forceps coagulation. To prevent a recurrence of bleeding, two clips (Instinct; Cook Medical, Bloomington, Indiana, USA) were placed on the coagulated area. Then, we attempted to catheterize the stent to remove clots with a sphincterotome ( Fig. 3 ), but this caused stent migration in the stomach. We used a duodenoscope to catheterize the hepaticogastric fistula and successfully placed the guidewire in the biliary tract. After opacification to confirm the position, a new partially covered stent was placed without bleeding or bile leakage. The patient's cholestasis rapidly decreased, and he has had no recurrence of bleeding or jaundice since then ( 2 months, at the time of writing).

Post-hepaticogastrostomy bleeding can also originate in the gastric wall and may induce stent dysfunction by clot obstruction. Endoscopic management appears to be possible with hot forceps hemostasis and stent exchange. The new stent enabled hemostasis by compression and restored effective biliary drainage.

Endoscopy_UCTN_Code_CPL_1AK_2AI

Competing interests: None 

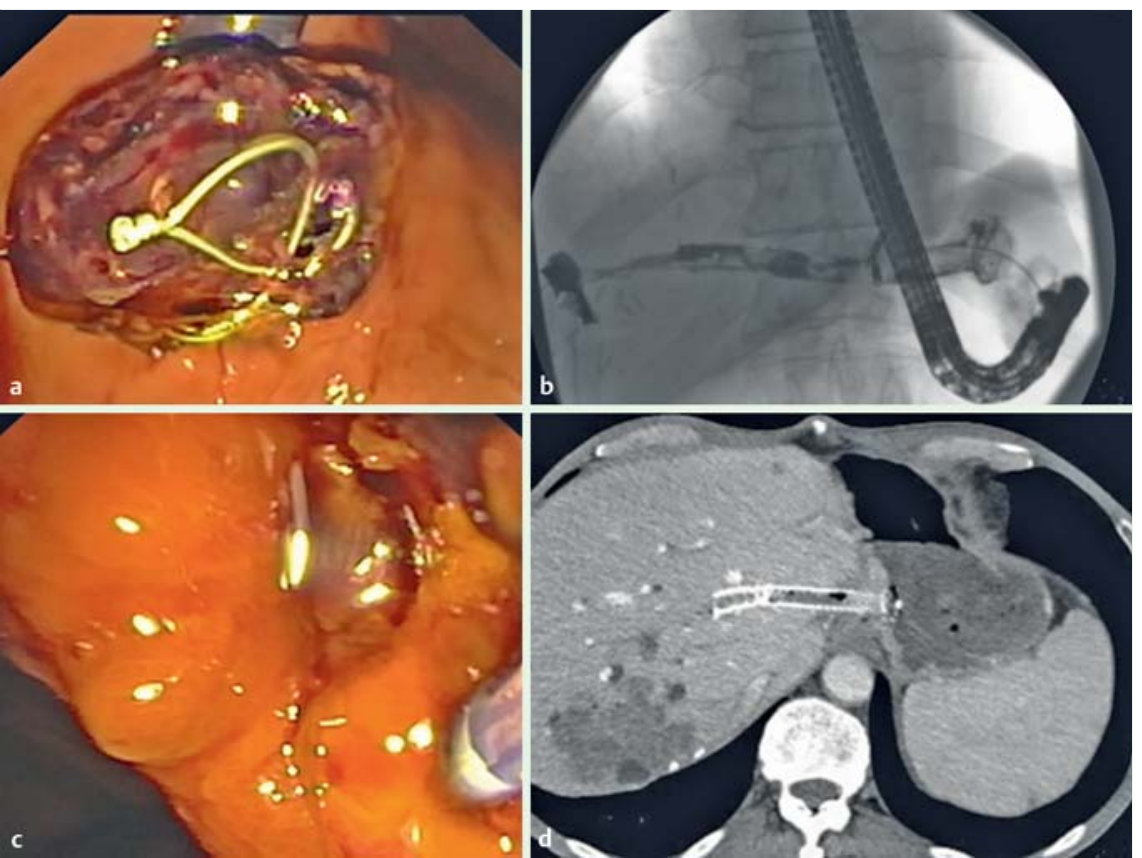

Fig. 3 Restored hepaticogastrostomy after stent migration. a Obstruction of the stent by blood clot. b Catheterization of the stent through the blood clot. c New catheterization after accidental stent migration. $\mathbf{d}$ CT appearance of the second partially covered stent.

\section{Caroline Fine ${ }^{1}$, Jérome Rivory ${ }^{1}$, Julien Forestier $^{2}$, Jean-Christophe Saurin ${ }^{3}$, Leonardo Sosa-Valencia ${ }^{1}$, Thierry Ponchon $^{1,4}$, Mathieu Pioche ${ }^{1,4}$}

${ }^{1}$ Departments of Endoscopy and Gastroenterology, Edouard Herriot Hospital, Lyon, France

2 Department of Digestive Oncology, Edouard Herriot Hospital, Lyon, France ${ }^{3}$ Department of Gastroenterology, Edouard Herriot Hospital, Lyon, France

${ }^{4}$ INSERM U1032, LabTau, Lyon, France

\section{References}

1 Giovannini M, Bories E. EUS-guided biliary drainage. Gastroenterol Res Pract 2012; 2012: 348719. DOI: $10.1155 / 2012 / 348719$

2 Hara K, Yamao K, Mizuno N et al. Endoscopic ultrasonography-guided biliary drainage: who, when, which, and how? World J Gastroenterol 2016; 22: 1297-1303

3 Okuno N, Hara K, Mizuno N et al. Stent migration into the peritoneal cavity following endoscopic ultrasound-guided hepaticogastrostomy. Endoscopy 2015; 47 (Suppl. 01): E311. DOI: $10.1055 / \mathrm{s}-0034-1392314$

4 Poincloux L, Rouquette O, Buc E et al. Endoscopic ultrasound-guided biliary drainage after failed ERCP: cumulative experience of 101 procedures at a single center. Endoscopy 2015; 47: 794-801

5 Prachayakul V, Thamtorawat S, Siripipattanamongkol $C$ et al. Bleeding left hepatic artery pseudoaneurysm: a complication of endoscopic ultrasound-guided hepaticogastrostomy. Endoscopy 2013; 45: E223-E224

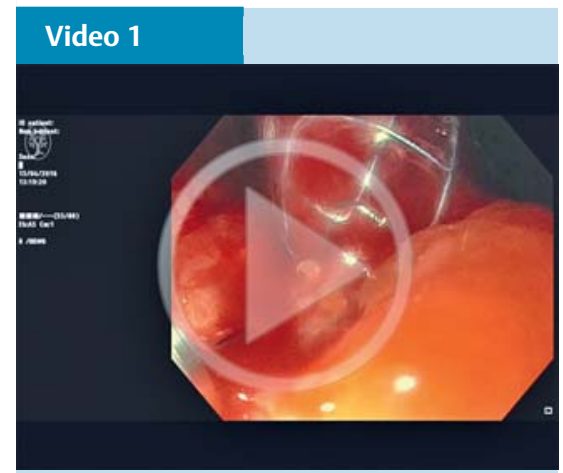

Hepaticogastrostomy in a patient with liver metastasis from colon cancer; 7 days later, endoscopic management of gastric wall bleeding with stent exchange.
Bibliography

DOI http://dx.doi.org/

10.1055/s-0042-118455

Endoscopy 2016; 48: E351-E352

(c) Georg Thieme Verlag KG

Stuttgart · New York

ISSN 0013-726X

\section{Corresponding author}

\section{Mathieu Pioche, MD}

Endoscopy Unit - Digestive Disease Department

Pavillon L - Edouard Herriot Hospital

69437 Lyon Cedex

France

Fax: +33-4-72110147

mathieu.pioche@chu-lyon.fr 